\title{
Similarity predicts liking in 3-year-old children
}

\author{
Christine A. Fawcett ${ }^{*, 1}$, Lori Markson ${ }^{2}$ \\ Department of Psychology, University of California, Berkeley, Berkeley, CA 94720, USA
}

\section{A R T I C L E I N F O}

\section{Article history:}

Received 6 March 2009

Revised 1 December 2009

Available online 22 January 2010

\section{Keywords:}

Social cognition

Social development

Friendship

Similarity

Preference

Peers

\begin{abstract}
A B S T R A C T
Two studies examined the influence of similarity on 3-year-old children's initial liking of their peers. Children were presented with pairs of childlike puppets who were either similar or dissimilar to them on a specified dimension and then were asked to choose one of the puppets to play with as a measure of liking. Children selected the puppet whose food preferences or physical appearance matched their own. Unpacking the physical appearance finding revealed that the stable similarity of hair color may influence liking more strongly than the transient similarity of shirt color. A second study showed that children also prefer to play with a peer who shares their toy preferences, yet importantly, show no bias toward a peer who is similar on an arbitrary dimension. The findings provide insight into the earliest development of peer relations in young children.
\end{abstract}

() 2009 Elsevier Inc. All rights reserved.

\section{Introduction}

What is the basis for friendships during early childhood? How do young children determine certain peers as potential friends to begin developing the bonds of friendship? For adults and adolescents, similarity between two individuals has been consistently found to be related to interpersonal liking and friendship. Predictors of initial liking and friendship include similarities in attitudes (Byrne \& Nelson, 1965; Neimeyer \& Mitchell, 1988), behaviors (Urberg, Degirmencioglu, \& Tolson, 1998), preferences (Billig \& Tajfel, 1973; Brewer \& Silver, 1978), and values and background (Johnson, 1989).

School-age children have also been shown to demonstrate a linear relationship between attitude similarity and initial attraction, identical to that seen in adults (Byrne \& Griffitt, 1966). That is, the

\footnotetext{
* Corresponding author.

E-mail address: christine.fawcett@mpi.nl (C.A. Fawcett).

1 Present address: Max Planck Institute for Psycholinguistics, 6500 AH Nijmegen, The Netherlands.

2 Present address: Department of Psychology, Washington University, St. Louis, MO 63130, USA.
} 
more opinions a child shares with another child, the more he or she will expect to like the other child. In addition, similarity in behavior has also been found to correlate with friendship during middle childhood (Haselager, Hartup, van Lieshout, \& Riksen-Walraven, 1998) and even to predict attraction to peers in young school-age children (Rubin, Lynch, Coplan, Rose-Krasnor, \& Booth, 1994). For example, 7-year-old children report more initial attraction to peers whose preferences (e.g., for activities or foods) are similar to their own (Reaves \& Roberts, 1983). Moreover, 3- to 9-year-old children who are able to establish common ground activities and explore each other's similarities and differences are more likely to become friends (Gottman \& Graziano, 1983). The basis of this similarity and liking phenomenon stems from similarity leading to friendship, not from friends becoming more similar over time. For example, Poulin and Boivin (2000) found that school-age boys were more similar in proactive aggression prior to becoming friends, with the degree of similarity remaining constant over the course of the friendship.

Thus, the relationship between similarity and initial attraction to peers has clearly been established for school-age children. However, there is currently little known about whether similarity is also a predictor of friendship in younger preschool-age children. This is surprising given that children begin to develop friendships long before reaching the school-age years. For example, Ross and Lollis (1989) found that 20- and 30-month-old children differed consistently in the interactions they both initiated with and elicited from specific peers, thereby showing individualized behavior and preferences for certain peers, an indicator of friendship. When friendship is defined by various behavioral measures, such as playing in close proximity, interacting socially, and sharing positive affect consistently with a particular peer, young children have been found to have at least one friend by 16 months of age and to have five or six friends by 3 years of age (Howes \& Phillipsen, 1992). In addition, Howes and Phillipsen (1992) examined similarity in gender, activity level, and social interaction style (e.g., gregarious, withdrawn) in these young friend pairs and found that, overall, cross-gender friends tended to be more similar in activity level and social interaction style compared with same-gender friends. This suggests that young children may be drawn toward peers of the same gender as well as cross-gender peers who are similar on other dimensions. However, because Howes and Phillipsen's study was based on observations of natural interactions, it is difficult to conclude whether these similarities played a role in children's initial attraction to each other.

Further evidence that gender plays a role in children's early choice of peers comes from studies with young preschoolers who typically elect to play with peers of the same gender (La Freniere, Strayer, \& Gauthier, 1984) and, moreover, predict that other children will do the same (Martin, Fabes, Evans, \& Wyman, 1999). This segregation begins just as children come to recognize their own gender (Fagot, 1985) and subsequently begin to show gender-based in-group favoritism and out-group denigration (Yee \& Brown, 1994). Although these findings suggest that children sometimes base friendships on similarity in gender, it is important to note that gender is likely confounded with other factors that play a role in the choice of friends. For example, children's toy preferences differ on the basis of gender from an early age (e.g., Weinraub et al., 1984), and children may simply prefer to play with peers who like the same toys as they do, rather than exhibiting a gender bias in attraction to peers. Thus, it is unclear how important gender and other aspects of similarity are to preschoolers, leaving open the question of whether children's attraction to same-gender peers is influenced by similarities in qualities such as preferences and appearance and, if so, whether different dimensions of similarity are weighted equally.

Developmental changes in children's conceptions of the foundation of friendship were explored in a study where 6- to 14-year-old children were asked to rate the important qualities in a friend (Bigelow, 1977). Younger children in the study tended to suggest common activities and proximity as important for friendship. In contrast, older children also cited "deeper" psychological qualities, such as loyalty and common interests, as important qualities in a friend. The findings suggest a developmental progression in how children describe those qualities they view as important for friendship. However, because the findings were based on children's verbal reports, it remains unknown whether children actually choose friends on the basis of such qualities differentially over development, reflecting a true change in what dimensions are relevant for initiating friendship.

The relative importance of different dimensions of similarity for initial attraction is also largely unexplored in the extant literature on adult friendship. In one relevant study, Neimeyer and Mitchell 
(1988) found that similar attitudes for superficial categories, such as music preferences, predicted initial attraction, whereas "deeper" similarities, such as personality and values, were better predictors for lasting friendships. This finding suggests that deeper internal qualities may be more relevant for friendship development in the long term than superficial qualities that may predict only initial attraction or a sense of "hitting it off" (Dishion, Patterson, \& Griesler, 1994). However, in Neimeyer and Mitchell's study, participants were not explicitly told which similarities existed between them and their partner; rather, they were simply asked to interact with each other for a designated period of time. Thus, it is possible that the participants did not discuss deeper similarities until later in the acquaintance process, explaining why these factors did not have an effect on early attraction. To our knowledge, no studies with children have compared the relative effects of different dimensions of similarity on attraction to others.

Previous research suggests that preschoolers have the ability to distinguish traits that are more internal and psychological versus external and superficial-a prerequisite for being able to differentially weight these dimensions when selecting potential friends. For example, 3 - and 4 -year-old children recognize that personality traits, rather than appearances, are useful predictors of behavior and preferences (Heyman \& Gelman, 2000). In addition, by 4 years of age, children expect traits to be stable over time and are capable of inferring trait labels from behaviors as well as predicting behavior on the basis of trait labels (Boseovski \& Lee, 2006; Liu, Gelman, \& Wellman, 2007). Do even younger preschoolers also rely on their understanding of personal characteristics and differentially weight various dimensions of similarity in the process of selecting potential friends?

Whereas research on early friendship suggests that interpersonal similarity might already play a role in the initiation of peer relationships (e.g., Howes \& Phillipsen, 1992; La Freniere et al., 1984), prior studies have relied on natural observations of young children, making it difficult to tease apart which qualities children tend to focus on in the selection of play partners who might later become friends. The current study explored, in a more controlled way, how the recognition of interpersonal similarity affects 3-year-old children's initial liking of same-gender peers as well as whether certain dimensions of similarity are more influential in this process. Because friendships can develop out of initial time spent playing with peers, determining how children choose peers to play with is important for beginning to examine the development of friendships. Controlling for gender enabled us to examine more carefully the dimensions of similarity that children view as relevant when gender is not involved. To our knowledge, this is the first study to systematically investigate the effect of different dimensions of similarity on preschool-age children's initial attraction to peers-the first step in the development of friendship.

\section{Experiment 1a}

Do 3-year-old children consider similarities between self and other when initiating play with peers? Experiment 1a examined whether similarity influences children's initial attraction to others by introducing them to interpersonal similarities on two dimensions: a shared personal preference and a match in physical appearance. We elected to focus on food preferences and hair/shirt colors as exemplars from these two dimensions because neither of these similarities is directly relevant for friendship in young children in terms of the behaviors they typically engage in with peers. That is, what children look like or the kinds of foods they enjoy would not necessarily be good indicators of whether they will play well together-choosing similar toys and type of play-and be compatible as friends. However, research with adults and older children suggests that initial interpersonal attraction is often influenced by similarities that are not especially relevant for long-term friendship such as a preference for a certain modern painter (Billig \& Tajfel, 1973) or similar political attitudes (Neimeyer \& Mitchell, 1988). Thus, it was possible that children in the current experiment would be influenced by similarities in food preferences and physical appearance.

Because these two dimensions include both an internal psychological similarity (preference) and an external perceptual similarity (appearance), we can begin to explore whether both internal and external features are influential in this process. In the experiment, children were introduced to pairs of lifelike gender-matched child puppets who were similar to or different from the children on one of the two dimensions, and their initial liking was then assessed by asking them to choose to play with 
one of the two puppets. If similarity on these dimensions influences children's initial liking for peers, the children should be drawn toward the more similar puppet.

\section{Method}

\section{Participants}

A group of 30 3-year-old children (15 girls and 15 boys) participated in the experiment (mean age $=3$ years 6 months, range $=3$ years 0 months to 3 years 11 months). An additional 4 children were excluded from the analyses for refusing to answer both test questions, and 2 children were excluded for parental interference. Participants were recruited from a database of families who expressed interest in participating in psychological research with their children, and they were tested in a university laboratory. Parents were offered a small gift for their child as compensation. The majority of the children in the final sample were European American $(n=16)$; among the other children, 4 were Asian American, 3 were Latino/a, 2 were African American, and the parents of 5 children declined to state their ethnicity.

\section{Design}

Children were presented with two pairs of lifelike gender-matched child puppets. One pair was used for each trial (food and appearance). Half of the children participated in the food trial first, and half participated in the appearance trial first. In the food trial, the similar puppet liked the same foods as the child, and the dissimilar puppet liked different foods. In the appearance trial, the similar puppet had the same hair and shirt color as the child, and the dissimilar puppet had different hair and shirt colors. After a series of control questions were asked to ensure that the child recognized the similarity between himself or herself and one of the puppets in each pair, the child was asked which puppet in each pair he or she would prefer to play with as a measure of initial liking. This forced-choice question was used in the experiment because it allowed a simple behavioral response (e.g., pointing to a puppet). Thus, it was expected to be easier for young children than a more explicit verbal response.

\section{Materials}

Four puppets, gender matched to the child, were used across the two trials (see Fig. 1). The puppets had blond, brown, or black hair and were dressed in solid color shirts (red, blue, green, yellow, pink, or white). Parents were asked to have their child wear a shirt in one of the six colors available for the puppets so that the similar puppet's shirt color could be matched to that of the child. Specifically, for the appearance trial, the puppet with the same color hair as the child was dressed in the color shirt that matched the child's. For the food trial, parents were asked to fill out a questionnaire to determine two foods their child liked and two foods their child disliked from a list of 20 possible items. The food choices consisted of a range of foods that children typically like (e.g., grapes) and dislike (e.g., asparagus). During the food trial, the selected foods were depicted with color illustrations.

\section{Procedure}

Food preference trial. The child sat at a table across from two female experimenters, each manipulating a puppet. Parents who brought their child to the university laboratory were present in the room during testing, sitting quietly behind their child without interfering. First, each experimenter introduced her puppet to the child. One experimenter then retrieved two pictures of different foods, one the child liked and one the child disliked, as designated earlier by parental report. One experimenter then asked the child which food he or she preferred to ensure that the child indeed liked the food the parents had selected. Each experimenter then asked each puppet which of the two foods he or she liked. The "similar" puppet claimed to like the same food the child liked (e.g., grapes), whereas the "dissimilar" puppet claimed to like the food the child did not like (e.g., asparagus). Then one experimenter highlighted the similarity, stating, "Oh, so you and [similar puppet] both like grapes, but [dissimilar puppet] likes asparagus." The same procedure was then repeated for the second pair of foods.

Appearance trial. After introducing the two puppets, one experimenter pointed out that the similar puppet was wearing a shirt the same color as the child's (e.g., blue). The puppet agreed, saying, 

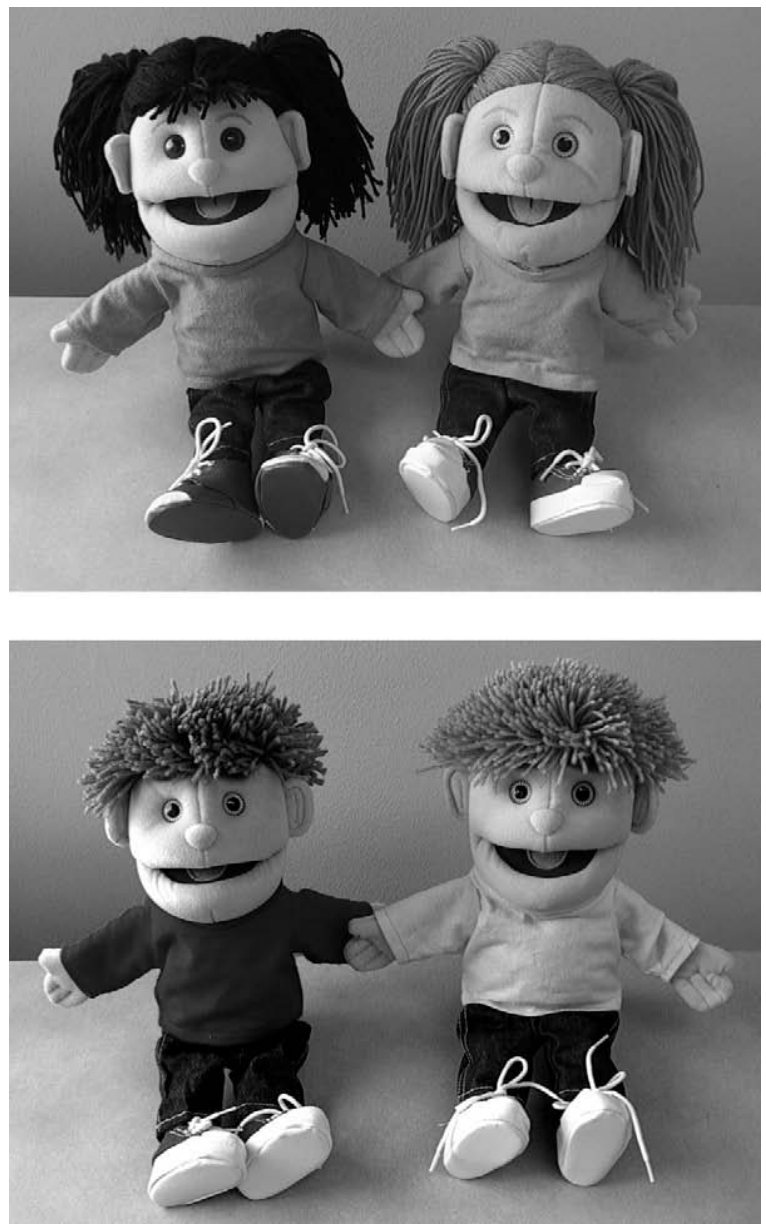

Fig. 1. Example pairs of girl and boy puppets used in all experiments.

"Yes, we both have blue shirts." The other experimenter pointed out that the dissimilar puppet had a different color shirt (e.g., yellow), and that puppet also agreed, saying, "Yes, I have a yellow shirt, not a blue one." The identical procedure was then used for hair color, pointing out that the similar puppet had the same color hair as the child and that the dissimilar puppet had a different color hair. Importantly, in both the food preference and appearance trials, the experimenters were trained to convey these comments with equal positivity and enthusiasm. Thus, there was no indication to children that similarity was more positive than dissimilarity.

Control questions. At the end of both the appearance and food preference trials, the child was asked control questions to ensure that he or she remembered the similar and dissimilar puppets' food preference or physical appearance qualities (e.g., "Who likes grapes?," "Who has a yellow shirt?") and recognized the similarity between himself or herself and one puppet (e.g., "Who likes to eat the same thing as you?," "Who has the same color shirt as you?").

Test question. Finally, at the end of each trial, one experimenter asked the child to choose one puppet to play with, saying, "You can choose one of these boys [girls] to play with. Which one would you like to play with?" 
The order of food preference and appearance trials and which experimenter asked the child each question was counterbalanced across children. For each child's two trials, whether the similarity or dissimilarity was mentioned first was also counterbalanced.

Results

Binomial tests were used to determine whether children's choices of which puppet to play with (similar vs. dissimilar) differed from chance. Children selected the similar puppet significantly more often than predicted by chance regardless of whether that similarity was in food preferences (mean $=.70$, binomial $p=.01$ ) or in physical appearance (mean $=.70$, binomial $p=.01$ ) (see Fig. 2 ). In addition, a chi-square analysis showed that the probability of choosing the similar puppet did not differ across the two dimensions of similarity, $\chi^{2}(1, N=30)=0.00, p=1.00$, or based on children's gender, $\chi^{2}(1, N=30)=0.00, p=1.00$.

\section{Discussion}

The results of Experiment 1a revealed that both food preference and physical appearance similarity were predictors of initial attraction in 3-year-old children. This experiment examined an internal psychological similarity, food preference, as well as an external physical similarity, hair and shirt color, and both similarities were found to affect children's choice of a peer to play with. This finding indi-

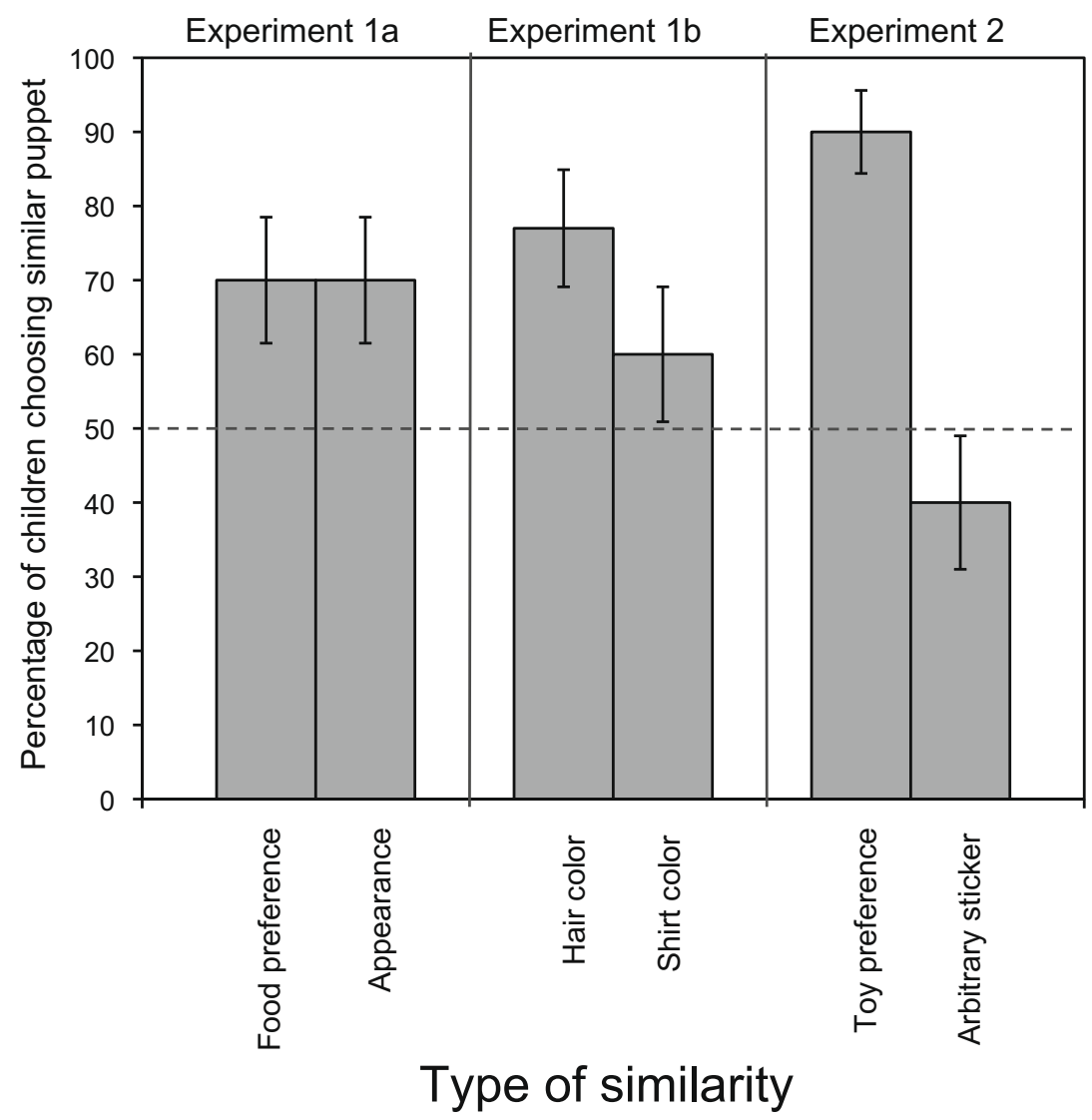

Fig. 2. Percentages of children choosing the similar puppet across different dimensions of similarity. 
cates that young children who are just beginning to form relationships with peers are already influenced by interpersonal similarities in their initial determination of whom to interact with, highlighting the potential role of interpersonal similarity in the early development of friendships. The results also suggest that a wide range of similarities may influence children's initial attraction to peers even if those similarities are not directly relevant to friendship. This finding is particularly interesting in light of the previous finding that 3- and 4-year-old children recognize that trait labels, but not appearances, are related to psychological characteristics (Heyman \& Gelman, 2000). Thus, although preschool-aged children understand that appearances are more superficial than traits, they may still be influenced by appearance when choosing potential friends.

It is important to note that in the appearance trial, it is unclear whether only one aspect of similar appearance, hair color or shirt color, may have driven this effect. One possibility is that children were influenced more by the stable quality of hair color, which could also serve as an indicator of ethnic background. In contrast, children might have been more strongly influenced by shirt color, especially if they viewed this dimension as a personal choice or a preference (e.g., "I chose to wear blue because it's my favorite color"). Finally, it is possible that both aspects of similar appearance affected children's initial attraction in the current situation. Experiment $1 \mathrm{~b}$ addressed this issue by testing the effect of each of these dimensions in isolation.

\section{Experiment 1b}

Experiment 1b was designed to tease apart which aspect(s) of physical appearance influenced children's initial liking of peers in Experiment 1a. To accomplish this, similarities on the dimensions of hair and shirt color were tested separately.

\section{Method}

\section{Participants}

A new group of 303 -year-old children (16 girls and 14 boys) participated in the experiment (mean age $=3$ years 4 months, range $=3$ years 0 months to 3 years 10 months). An additional child was excluded from the analyses for refusing to answer both test questions. Participants were recruited from and tested in urban preschools $(n=6)$ or from a database of families who had expressed interested in participating in research with their child and tested in a university laboratory $(n=24)$. Parents who brought their child to the university to participate were offered a small gift for their child as compensation. The majority of children in the final sample were European American $(n=16)$; among the other children, 4 were Asian American, 2 were Latino/a, and the parents of 8 children declined to state their ethnicity.

Design

The design was identical to that of Experiment 1a with the exception that in each trial only one similarity was presented (either hair color or shirt color).

\section{Materials}

The materials were identical to those used for the appearance trial of Experiment 1a.

\section{Procedure}

The procedure was identical to that for the appearance trial of Experiment 1a except that in each of the two trials only one aspect of appearance was manipulated (either hair color or shirt color). Specifically, in the hair color trial, the two experimenters pointed out the similarity and difference in the hair colors of the child and puppets; in the shirt color trial, they pointed out the similarity and difference in shirt colors. In each trial, neither puppet's nonemphasized dimension matched the child's (e.g., in the shirt color trial, neither puppet had the same hair color as the child).

The child was asked control questions to ensure that he or she remembered the similar and dissimilar puppets' qualities (e.g., "Who has brown hair?," "Who has a blue shirt?") and that they recognized 
the similarity between himself or herself and one of the puppets (e.g., "Who has the same color hair as you?," "Who has the same color shirt as you?"). Finally, at the end of each trial, one experimenter asked the child to choose one puppet to play with.

\section{Results}

Binomial tests were used to determine whether children's choices of which puppet to play with (similar vs. dissimilar) differed from chance. Children chose the puppet with the same hair color (mean $=.77$, binomial $p=.002$ ) significantly more often than predicted by chance, but they were only marginally more likely to choose the puppet wearing the same color shirt (mean $=.60$, binomial $p=.08$ ) (see Fig. 2). Thus, children's initial liking appears to be influenced by similarity in hair color and possibly also by similarity in shirt color.

A chi-square analysis revealed that the likelihood of selecting the similar puppet did not differ significantly across the two types of similarity (hair and shirt color), $\chi^{2}(1, N=30)=1.93, p=.17$, or based on children's gender, $\chi^{2}(1, N=30)=0.08, p=.78$. This result suggests that children were not influenced significantly more by similarity in hair color than in shirt color.

\section{Discussion}

Experiment 1b clearly revealed that similarity in hair color influences 3-year-old children's initial attraction to peers. Even though hair color does not have direct relevance for playmates or friendship, it is a relatively permanent physical characteristic. Thus, children in the current task may have viewed it as a stable personal characteristic, leading them to consider it a meaningful factor when selecting potential playmates.

The findings on shirt color similarity are less definitive than those on hair color. Children were only marginally more likely to choose the puppet who was wearing the same color shirt, yet this rate of choosing did not differ significantly from that of hair color. Even though similarity in clothing color could be interpreted as an indicator of preference for certain colors over others, not every color that one wears is a "favorite" and some children at this age do not even select their own clothes to wear. Thus, a match in shirt color might not be a strong preference similarity for many children, resulting in a less clear influence on liking. Overall, the results of Experiment $1 \mathrm{~b}$ suggest that similar hair color was likely driving the effect of similar appearance obtained in Experiment 1a, although shirt color may have contributed to this effect.

\section{Experiment 2}

The results of Experiment 1 showed that when children choose peers to play with, they take into account interpersonal similarity on both internal (food preferences) and external (appearance) dimensions. Because these dimensions are not necessarily directly relevant for play and friendship for children, it seems reasonable to hypothesize that children's attraction to peers would also be influenced by similarity on dimensions that are relevant for friendship, for example, style of play (e.g., gentle vs. rough) and toy preferences (e.g., dolls vs. trucks). But do children discriminate between-and thus weight more heavily-dimensions of similarity that are differentially related to friendship? For example, would children be more likely to choose to play with peers who like the same toys as they do than peers who like the same foods as they do? Preferences for particular toys could be especially important for choosing playmates because children's early friendships typically involve shared play. On the other hand, children could be equally influenced by a range of similarities. A further question that arises is whether there might be similarities that children attend to but that do not influence their choice in playmates. For example, if a similarity is arbitrary-it is neither stable nor a personal preference-does it hold the potential to influence children's initial attraction to peers?

To address these questions, children in Experiment 2 were presented with puppets who were similar to or different from them on two new dimensions: toy preferences and type of sticker received from the experimenter. Thus, one dimension of similarity (toy preference) was designed to be relevant 
for play and friendship, whereas the other dimension (sticker received) was designed to be arbitrary because it was randomly assigned in the moment-neither a choice nor a personal characteristic. These two dimensions also mirror those in Experiment 1 in that each child was presented with one preference trial (toys), representing an internal characteristic, and one perceptual trial (stickers), representing an external characteristic. However, in the current experiment, the preference similarity was more directly relevant for friendship than in Experiment 1, and the perceptual similarity, which was determined arbitrarily, was irrelevant for friendship.

If children are sensitive to the relevance of particular similarities when selecting play partners, they should choose to play with the puppet who shares their toy preference but not one who just happened to receive the same sticker. In addition, when compared with children's choices in Experiment 1, children were predicted to be even more likely to select a puppet who shares their toy preferences than one who shares their food preferences or is similar in physical appearance because toy preferences are likely to be viewed as the most relevant dimension of similarity for play and potential friendship.

\section{Method}

\section{Participants}

A new group of 30 3-year-old children (15 girls and 15 boys) participated in the experiment (mean age $=3$ years 5 months, range $=2$ years 11 months to 3 years 10 months). An additional 4 children were excluded from the analyses for refusing to answer both test questions. Participants were recruited and tested in preschools $(n=16)$ or a university laboratory $(n=14)$ as in Experiment $1 \mathrm{~b}$. The majority of the children in the final sample were European American $(n=16)$; among the other children, 5 were Asian American, 4 were Latino/a, 2 were African American, and the parents of 3 children declined to state their ethnicity.

\section{Design}

The design was identical to that of Experiment 1 with the exception that the preference similarity was on the dimension of toys and the perceptual similarity was arbitrarily receiving a sticker of the same color and shape as the similar puppet (and different color and shape as the dissimilar puppet).

\section{Materials}

The same puppets were used as in Experiment 1. The puppets had different hair and shirt colors so that they were easily distinguishable. For the toy trial, a questionnaire was given to parents beforehand to determine each child's two most liked toys from a selection of six possible small toys (stuffed dog, dinosaur, Dora the Explorer, baby doll, Thomas the Train, and truck). The child's two liked toys were used to demonstrate the toy preference of the similar puppet. Each of the child's liked toys was paired with a plain toy (stick or block) to demonstrate the preference of the dissimilar puppet. For the sticker trial, a sticker of the same shape (star or circle) and color (red, blue, or yellow) was given to the child and to the similar puppet, and a sticker of a different shape and color was given to the dissimilar puppet.

\section{Procedure}

Toy trial. The toy preference trial was identical to the food preference trial of Experiment 1. Specifically, the child was first shown a liked toy paired with a plain toy and was asked which one he or she preferred to confirm that the child liked the expected toy. ${ }^{3}$ The two experimenters continued by asking each puppet his or her opinion about the pairs of toys (one liked and one disliked by the child) and pointing out the similarities and differences between the child and the puppet.

Sticker trial. The sticker trial was identical to the physical appearance trial of Experiment 1 with the exception that after introducing the two puppets at the beginning of each trial, one experimenter took

\footnotetext{
${ }^{3}$ In a total of two trials, a child claimed to prefer the plain toy, so in those cases the similar puppet also claimed to like the plain toy.
} 
Table 1

Characteristics of the logistic regression model.

\begin{tabular}{lrlllrl}
\hline Predictor & $\beta$ & SE $\beta$ & Wald's $\chi^{2}$ & $d f$ & $p$ & Odds ratio \\
\hline Food preference & & & 14.94 & 3 & .002 & \\
Appearance & 0.00 & .56 & 0.00 & 1 & 1.000 & 1.000 \\
Sticker & -1.25 & .55 & 5.27 & 1 & .020 & 0.286 \\
Toy preference & 1.35 & .73 & 3.44 & 1 & .060 & 3.860 \\
Constant & 0.85 & .40 & 4.52 & 1 & .030 & 2.330 \\
\hline
\end{tabular}

out three stickers (two that were the same shape and color [e.g., yellow stars] and one that was different [e.g., red circle]). She placed one of the matching stickers on the hand of the similar puppet and placed the other on the hand of the child, and she placed the different sticker on the hand of the dissimilar puppet. Then, as in Experiment 1, the two experimenters pointed out that one puppet had the same color of sticker as the child and the other puppet had a different color sticker and that one puppet had the same shape of sticker as the child and the other puppet had a different shape sticker.

Control questions. After both the toy trial and the sticker trial, the child was asked control questions to ensure that he or she remembered the similar and dissimilar puppets' toy preferences or sticker qualities (e.g., "Who likes the dinosaur?," "Who has a yellow sticker?") and recognized the similarity between himself or herself and one puppet (e.g., "Who likes the same toy as you?," "Who has the same color sticker as you?").

Test question. At the end of each trial, one experimenter asked the child to choose one puppet to play with by saying, "You can choose one of these boys [girls] to play with. Which one would you like to play with?"

The order of toy preference and sticker trials and which experimenter asked the child each question was counterbalanced across children. For each child, whether the similarity or dissimilarity was mentioned first was also counterbalanced. In addition, the color and shape of sticker assigned as the match and mismatch were randomly assigned across children.

\section{Results}

Binomial tests were used to determine whether children's choices of which puppet to play with (similar vs. dissimilar) differed from chance. The tests revealed that children chose to play with the puppet whose toy preferences were similar to their own more often than expected by chance (mean $=.90$, binomial $p<.0001$ ). However, in the sticker trial, there was a marginally significant trend for children to choose the puppet with a different sticker (mean $=.40$, binomial $p=.08$ ) (see Fig. 2 ). A chi-square analysis further revealed that children were more likely to select the similar puppet in the toy preference trial than in the sticker trial. $\chi^{2}(1, N=30)=14.36, p<.0001$, but choices did not differ based on children's gender. $\chi^{2}(1, N=30)=0.07, p=.79$.

Binomial logistic regression was used to examine the effect of the different aspects of similarity across Experiments 1 and 2 (food preference, appearance, toy preference, and sticker) on the proportion of choices of the similar versus dissimilar puppet. ${ }^{4}$ The overall model with the four aspects of similarity as predictors was significant, $\chi^{2}(3, N=120)=18.15, p<.0001$, and revealed that across the two experiments, children were significantly less likely to choose the similar puppet in the sticker trial $\left(\beta=-1.25\right.$, Wald's $\left.\chi^{2}=5.27, p=.02\right)$ than in the food preference and appearance trials, in which children chose the similar puppet equally often $\left(\beta=0.00\right.$, Wald's $\left.\chi^{2}=0.00, p=1.00\right)$. In addition, children were marginally more likely to choose the similar puppet in the toy preference trial $(\beta=1.35$, Wald's $\chi^{2}=3.44, p=.06$ ) than the food preference and appearance trials (see Table 1 for the characteristics of

\footnotetext{
${ }^{4}$ Because Experiment 1 was run with children solely in the university laboratory setting and Experiment 2 was run partially in a preschool setting, a chi-square test was conducted to ensure that there were no systematic differences between the two populations of children tested in the two locations, $\chi^{2}(1, N=60)=0.07, p=.79$.
} 
the model). Because it is possible that each participant's two responses might not have been completely independent, a mixed-effect model was also fit to the data using the lmer function of the R package lme4 (Bates, 2005; Bates \& Sarkar, 2007; R Development Core Team, 2005). This model included a random intercept for the participant factor, which accounted for any nonindependence among each participant's responses (Baayen, Davidson, \& Bates, 2008) and gave results identical to those from the initial binomial logistic regression. Together, these analyses suggest that children show rather sophisticated discrimination about the relevance of different dimensions of similarity for play and potential friendship.

\section{Discussion}

In Experiment 2, 3-year-old children's choice of whom to play with was influenced by similarity in toy preferences but not by the arbitrary similarity of having randomly received the same sticker. In addition, compared with Experiment 1, children were marginally more likely to choose similar peers to play with when the dimension of similarity was toy preference as compared with food preference or physical appearance. That children of this age are influenced by interpersonal similarity at all is interesting, but the finding that they appear to be sensitive to the subtleties of this gradation is quite striking. Overall, these results suggest that children have sophisticated intuitions about the dimensions of similarity that matter for establishing friendships. Children place high value on similarity in toy preferences, and this makes sense given that it would foster compatible play with peers and is in line with previous findings that link activity preferences to friendship in older children (Reaves \& Roberts, 1983). Food preferences are less directly relevant for friendship, yet they are still an internal psychological characteristic and personal preferences help to define who we are as individuals. Physical appearance, although an external feature with less direct relevance for friendship than preference, can still reflect stable characteristics (e.g., hair color) or choices (e.g., shirt color) that may be part of a child's self-image. In contrast, an arbitrary and temporary similarity has no predictive value for how compatible two people are likely to be.

Interestingly, adults have been found to show some in-group favoritism for randomly assigned groups (e.g., Brewer \& Silver, 1978), yet the young children in the current experiment were not swayed by a random arbitrary similarity. Children showed no bias to choose to play with peers who had been given the same color and shape of sticker. In fact, children were marginally more likely to select peers with a different sticker than their own, suggesting that children may actually crave variety when the dimension of similarity is not a relevant or personal one. The finding that children of this age are not influenced by every type of similarity when selecting playmates also serves as an important control condition in that it demonstrates that there was not some aspect of our experimental method that led children to choose similar peers. Along these lines, children were not simply influenced by the statements of similarity (or dissimilarity) made during the experiment given that those were identical across conditions. Rather, children are sensitive to the importance of various dimensions of interpersonal similarity, with those dimensions that are more relevant for friendship influencing children's liking of their peers more strongly.

\section{General discussion}

The current findings suggest that from a young age, children use similarity as a cue to the likelihood of friendship. That is, they tend to select peers who are similar to them when choosing whom to play with. This finding complements and extends previous observational findings suggesting that young children's peer choices might be based on interpersonal similarities (Howes \& Phillipsen, 1992). Interestingly, our findings also reveal that not all dimensions of similarity are equally powerful. Specifically, although both internal psychological similarities and external physical similarities have an influence on initial attraction, the influence of a particular aspect of similarity appears to differ based on the relevance of that property. For example, different kinds of personal preferences and physical attributes, such as hair color, have a strong impact on children's liking of peers, and temporary physical characteristics, such as clothing, may also have an influence. Yet a completely arbitrary similarity of having received the same sticker from an adult does not increase attraction at all. In fact, children 
might even prefer dissimilarity on an arbitrary dimension. Thus, children appear to appreciate the relevance of the quality in question such that they are more strongly influenced by similarities that are likely to be consistent over time and that have the potential to indicate future friendship as compared with similarities that are fleeting or less indicative of future social relations.

Shared preferences may be essential for friendship because they are indicative of common interests and potential for shared activities. Being able to share preferred activities, such as playing tennis, going to art museums, and eating at certain restaurants, may be more important in a friend than sharing attitudes on political or social issues, which are often used in similarity and liking studies with adults (e.g., Byrne \& Nelson, 1965). Children in the current study overwhelmingly chose to play with peers who preferred the same toys they did, and this could suggest recognition of the importance of shared play activities with friends, which is thought to be an important developmental task at this age (e.g., Sroufe, 1979). However, children also tended to choose peers who liked the same foods they did. Because children of this age are certainly not choosing restaurants to visit with their friends, this finding could indicate a more general sense that shared preferences are important for friendship regardless of the content of that preference.

These findings raise the question of whether choosing friends on the basis of similarity is an explicit rational strategy or a more intuitive emotional one. A rational selection of friends based on interpersonal similarity would involve individuals selecting others as potential friends based on explicit reasoning about potential friendship success. In contrast, Dishion and colleagues (1994) argued that interpersonal similarity, in terms of shared interests and common ground, may simply lead to an initial emotional sense of hitting it off with someone that begins the process of becoming friends. This initial feeling of connection can subsequently lead to the discovery of more similarities and the establishment of a friendship. Thus, recognition of a particular interpersonal similarity might not be a guarantee of future friendship, but it may at least indicate that a friendship is a possibility, explaining why even similarities that are seemingly unimportant for children's friendships, such as food preferences, might still have an impact on initial attraction. This theory makes sense in light of the finding that adults' initial attraction is determined by superficial similarities, whereas subsequent friendship development is predicted by deeper similarities such as values (Neimeyer \& Mitchell, 1988).

The view that initial peer attraction is based on an emotional intuition may also provide an alternative explanation for the greater influence of toy preferences over food preferences on liking. It is possible that children were more interested in and excited by the toys than the foods, sparking a stronger emotional sense of having hit it off with similar peers and increasing the likelihood of choosing them to play with. Although our current findings cannot tease apart these two explanations, they raise interesting questions for future research.

In addition to preferences, stable physical characteristics were found to influence children's choices of whom to play with in the current study. Although it is not clear why a physical characteristic, such as hair color, could be indicative of future friendship, it is possible that the salience of hair color similarity is enough to make it important to young children. Children observe their own hair color every time they look in a mirror or see a photograph of themselves. ${ }^{5}$ Thus, seeing peers with that same hair color may have been significant for them. This explanation would also fit with the idea that similarity has a more intuitive than rational effect on liking.

An implication of the finding that hair color similarity leads to liking is that it could lead to peer segregation based on race. Even though all of the puppets in the current study had light-colored skin, their hair color could be interpreted as an indicator of race. More generally, the implication is that if children select friends based on similar physical characteristics, such as hair color, they will be less likely to develop cross-race friendships. Some research suggests that elementary school children prefer same-race peers and rate them more highly on sociometric scales than peers of other races (Graham \& Cohen, 1997). However, in racially heterogeneous schools, less racial bias is seen at this age. For example when there is no majority race in a school, children select equal numbers of same- and crossrace friends (Aboud, Mendelson, \& Purdy, 2003) and are equally likely to predict friendship between

\footnotetext{
${ }^{5}$ In addition, only a very small number of children in our study needed help to answer the question, "Who has the same color hair as you?," suggesting that at this age children do have knowledge of their own hair color.
} 
same- and cross-race pairs of children (McGlothlin, Killen, \& Edmonds, 2005). Thus, although there may be some evidence for a similarity-liking bias based on race, children who experience racial diversity among peers may learn that race is not a similarity that is predictive of friendship and, thus, no longer use it as a cue for attraction.

One limitation of the current study is that it may have yielded different results with real children instead of puppets as the similar and dissimilar peers. Although the use of puppets allowed the control of many potentially confounding factors in the study, it could be construed as distracting from the authenticity of the situation. However, puppets are frequently used in developmental research with children of this age, and children in the current study appeared to be genuinely enamored of the puppets, responding to them more as children than as dolls. Many children spoke to the puppets spontaneously, for example, answering back when the puppets said "hello" to them at the beginning of each trial.

Another potential explanation for children's choices is that they might not reflect recognition of similarity in characteristics per se but rather might reflect children's tendency to choose peers who have characteristics they find attractive. That is, children may simply be attracted to others who like the foods and toys they like without truly recognizing a shared preference. This explanation is somewhat weakened by the finding that children also chose peers with the same hair color given that children do not choose, and thus may not prefer, their own hair color. In addition, recent findings suggest that 2-year-old children can recognize and reason about preferences they share with others (Fawcett \& Markson, in press).

A third possible explanation for the similarity-attraction findings in the current study is that, rather than recognizing and being influenced by the similarities themselves, children were simply biased by the statements of similarity and dissimilarity made during the study (e.g., "You and Robyn both have brown hair, but Beth has blond hair"). However, this explanation cannot account for the findings of the sticker condition in which the dimension of similarity was arbitrary. That is, despite the fact that the exact same statements were made regarding similarity and dissimilarity, children in this condition were not biased to choose similar peers. Whereas the current findings cannot be accounted for by children's reliance on others' statements concerning similarity, an interesting area for future research is to examine precisely which interpersonal similarities children spontaneously notice in their peer interactions when such statements are not explicitly provided.

Finally, it is not possible to infer from the current findings whether children are attracted to similar peers or averse to dissimilar peers. Research findings on this issue with adults are mixed. Some findings suggest that similarity has a stronger influence on attraction than dissimilarity has on repulsion (e.g., Singh \& Tan, 1992), whereas others suggest the opposite (e.g., Singh \& Ho, 2000). Further exploration of this issue from a developmental perspective is another fruitful area for future research.

The current findings contribute to the literature on children's understanding of personality and dispositions. Research in this field suggests that preschool-aged children are just beginning to think of others as having stable characteristics that are predictive of behavior (Boseovski \& Lee, 2006; Heyman \& Gelman, 2000; Liu et al., 2007). The current study adds to this that young children also use their knowledge of others' characteristics, particularly characteristics similar to their own, in their selection of peers to interact with. In other words, children's recognition of others' personal characteristics further influences their initial liking of those individuals.

The findings of the current study give insight into children's early developing peer relations and friendships. As young children begin to exhibit preferences for certain peers over others (Howes \& Phillipsen, 1992; Ross \& Lollis, 1989), their initial attraction to others is already influenced by interpersonal similarity. The current research extends previous findings linking similarity to initial liking in older children and adults to a considerably younger population. In addition, these findings reveal that young children are selective about the dimensions of similarity they view as important for play and potential friendship. Children place a high value on those qualities deemed to be most relevant for their interactions with peers and characteristics that remain stable over time. Thus, even during the preschool years, children are capable of making sophisticated social choices that lay the foundation for the development of deeper friendships. 


\section{References}

Aboud, F. E., Mendelson, M. J., \& Purdy, K. T. (2003). Cross-race peer relations and friendship quality. International Journal of Behavioral Development, 27, 165-173.

Baayen, R. H., Davidson, D. J., \& Bates, D. M. (2008). Mixed-effects modeling with crossed random effects for subjects and items. Journal of Memory and Language, 59, 390-412.

Bates, D. (2005). Fitting linear models in $\mathrm{R}$ using the lme4 package. $R$ News, 5(1), 27-30.

Bates, D., \& Sarkar, D. (2007). lme4: Linear mixed-effects models using S4 classes. R package, version 0.9975-13.

Bigelow, B. J. (1977). Children's friendship expectations: A cognitive-developmental study. Child Development, 48, $246-253$.

Billig, M., \& Tajfel, H. (1973). Social categorization and similarity in intergroup behavior. European Journal of Social Psychology, 3 , 27-52.

Boseovski, J. J., \& Lee, K. (2006). Children's use of frequency information for trait categorization and behavioral prediction. Developmental Psychology, 42, 500-513.

Brewer, M. B., \& Silver, M. (1978). Ingroup bias as a function of task characteristics. European Journal of Social Psychology, 8, 393-400.

Byrne, D., \& Griffitt, W. (1966). A developmental investigation of the law of attraction. Journal of Personality and Social Psychology, 4, 699-702.

Byrne, D., \& Nelson, D. (1965). Attraction as a linear function of proportion of positive reinforcements. Journal of Personality and Social Psychology, 1, 659-663.

Dishion, T. J., Patterson, G. R., \& Griesler, P. C. (1994). Peer adaptation in the development of antisocial behavior: A confluence model. In L. R. Huesmann (Ed.), Aggressive behavior: Current perspectives (pp. 61-95). New York: Plenum.

Fagot, B. I. (1985). Beyond the reinforcement principle: Another step toward understanding sex role development. Developmental Psychology, 21(6), 1097-1104.

Fawcett, C.A., \& Markson, L. (in press). Children reason about shared preferences. Developmental Psychology.

Gottman, J. M., \& Graziano, W. G. (1983). How children become friends. Monographs of the Society for Research in Child Development, 48(3, Serial No. 201), 1-86.

Graham, J. A., \& Cohen, R. (1997). Race and sex as factors in children's sociometric ratings and friendship choices. Social Development, 6, 355-372.

Haselager, G. J., Hartup, W. W., van Lieshout, C. F., \& Riksen-Walraven, J. M. (1998). Similarities between friends and nonfriends in middle childhood. Child Development, 69, 1198-1208.

Heyman, G. D., \& Gelman, S. A. (2000). Preschool children's use of trait labels to make inductive inferences. Journal of Experimental Child Psychology, 77, 1-19.

Howes, C., \& Phillipsen, L. (1992). Gender and friendship: Relationships within peer groups of young children. Social Development, 1, 230-242.

Johnson, M. A. (1989). Variables associated with friendship in an adult population. Journal of Social Psychology, 129, 379-390.

La Freniere, P., Strayer, F. F., \& Gauthier, R. (1984). The emergence of same-sex affiliative preferences among preschool peers: A developmental/ethological perspective. Child Development, 55, 1958-1965.

Liu, D., Gelman, S. A., \& Wellman, H. M. (2007). Components of young children's trait understanding: Behavior-to-trait inferences and trait-to-behavior predictions. Child Development, 78, 1543-1558.

Martin, C. L., Fabes, R. A., Evans, S. M., \& Wyman, H. (1999). Social cognition on the playground: Children's beliefs about playing with girls versus boys and their relations to sex segregated play. Journal of Social and Personal Relationships, 16, 751-771.

McGlothlin, H., Killen, M., \& Edmonds, C. (2005). European-American children's intergroup attitudes about peer relationships. British Journal of Developmental Psychology, 23, 227-249.

Neimeyer, R. A., \& Mitchell, K. A. (1988). Similarity and attraction: A longitudinal study. Journal of Social and Personal Relationships, 5, 131-148.

Poulin, F., \& Boivin, M. (2000). The role of proactive and reactive aggression in the formation and development of boys. Developmental Psychology, 36, 233-240.

R Development Core Team. (2005). R: A language and environment for statistical computing. Vienna, Austria: Foundation for Statistical Computing.

Reaves, J. Y., \& Roberts, A. (1983). The effect of type of information on children's attraction to peers. Child Development, 54, 1024-1031.

Ross, H. S., \& Lollis, S. P. (1989). A social relations analysis of toddler peer relationships. Child Development, 60, $1082-1091$.

Rubin, K. H., Lynch, D., Coplan, R., Rose-Krasnor, L., \& Booth, C. L. (1994). "Birds of a feather. ..": Behavioral concordances and preferential personal attraction in children. Child Development, 65, 1778-1785.

Singh, R., \& Ho, S. Y. (2000). Attitudes and attraction: A new test of the attraction, repulsion, and similarity-dissimilarity asymmetry hypotheses. British Journal of Social Psychology, 39, 197-211.

Singh, R., \& Tan, L. S. C. (1992). Attitudes and attraction: A test of the similarity-attraction and dissimilarity-repulsion hypotheses. British Journal of Social Psychology, 31, 227-238.

Sroufe, L. A. (1979). The coherence of individual development. American Psychologist, 34, 834-841.

Urberg, K. A., Degirmencioglu, S. M., \& Tolson, J. M. (1998). Adolescent friendship selection and termination: The role of similarity. Journal of Social and Personal Relationships, 15, 703-710.

Weinraub, M., Pritchard Clemens, L., Sockloff, A., Ethridge, T., Gracely, E., \& Myers, B. (1984). The development of sex role stereotypes in the third year: Relationships to gender labeling, gender identity, sex-typed toy preference, and family characteristics. Child Development, 55, 1493-1503.

Yee, M., \& Brown, R. (1994). The development of gender differentiation in young children. British Journal of Social Psychology, 33, 183-196. 